\title{
Educação em valores morais: juízos de profissionais no contexto escolar
}

\author{
Heloisa Moulin de Alencar \\ Universidade Federal do Espírito Santo - ES \\ Barbara Frigini De Marchi \\ Universidade Federal do Espírito Santo - ES \\ Leandra Lúcia Moraes Couto \\ Universidade Federal do Espírito Santo - ES \\ Mariana Santolin Romaneli \\ Universidade Federal do Espírito Santo - ES \\ Mayara Gama de Lima \\ Universidade Federal do Espírito Santo - ES
}

\begin{abstract}
Resumo
Esta pesquisa teve como objetivo investigar os juízos de profissionais da educação como professores, diretores, coordenadores, pedagogos e supervisores pedagógicos, de escolas estaduais de Ensino Fundamental (6. ${ }^{\circ}$ ao $9 .{ }^{\circ}$ ano) e Médio do Espírito Santo, sobre educação em valores morais (EVM). Utilizou como instrumento de coleta de dados um questionário, enviado a escolas via correio e disponibilizado on-line. A partir dos dados, constatou que a maior parte da amostra: (1) afirmou que a EVM trabalha os "valores morais ou éticos"; (2) considerou que a instituição escolar deve dar esse tipo de educação; (3) argumentou que a instituição de ensino deve formar moralmente, porque essa "é a função da escola"; e (4) mencionou como possibilidade de procedimento para EVM os métodos verbais e ativos. Assim, apontou que os participantes reconheceram a importância da instituição de ensino no processo de desenvolvimento moral dos alunos.
\end{abstract}

Palavras-chave: Educação, ética, escola.

\section{Education in moral values: judgments of professionals in the educational context}

\begin{abstract}
This study aims to investigate the judgments of Education professionals, such as teachers, principals, coordinators, pedagogical supervisors and pedagogues in fundamental public schools (6th to 9th grades) and secondary education in Espírito Santo, regarding education related to moral values (EMV). We used a questionnaire as an instrument for data collection, mailed and made available online. From the data, it was noted that the majority of the sample (1) stated that EMV addresses the "moral or ethical values" (2) considered that schools should provide this kind of education, (3) argued that the educational institution should educate morally because this "is the function of the school" and (4) mentioned as a possible procedure for EVM, the verbal and active methods. Thus, it was pointed out that the participants recognized the importance of the educational institution in the process of moral development of the students.
\end{abstract}

Keywords: Education, ethics, school.

\section{Educación en valores morales: juicios de profissionales en el contexto escolar}

\section{Resumen}

Esta investigación tuvo como objetivo investigar los juicios de profesionales de educación - profesores, directores, coordinadores, pedagogos y supervisores pedagógicos - de escuelas estatales de Enseñanza Fundamental ( $6^{\circ}$ a $9^{\circ}$ años) y Enseñaza Media de Espírito Santo al respecto de la educación en valores morales (EVM). Utilizó como instrumento de recolección de datos un cuestionario enviado por correo y disponibilizado online. A partir de los datos se constató que la mayor parte de la muestra: 1- afirmó que la EVM trabaja los "valores morales o éticos"; 2- consideró que la institución escolar debe dar ese tipo de educación; 3- argumentó que la institución de enseñanza deve formar moralmente porque esa "es la función de la escuela"; y 4- mencionó como posibilidad de procedimiento para EVM los métodos verbales y activos. Así, indicó que los participantes reconocieron la importancia de la institución de enseñanza en el proceso de desarrollo moral de los alunos.

Palabras clave: Educación, ética, escuela. 


\section{Introdução}

Este artigo é parte de um estudo realizado no Estado do Espírito Santo, que buscou investigar e descrever experiências de educação em valores morais ${ }^{1}$ (EVM) mediante as concepções, juízos e práticas de profissionais do contexto escolar. Apresentamos, no presente trabalho, os dados e análises a respeito das concepções e juízos dos participantes sobre a EVM.

Visto que a área da EVM é ampla, torna-se fundamental esclarecermos inicialmente alguns conceitos. Para tanto, retomamos autores da Psicologia da Moralidade e discutimos os termos moral e ética. Embora esses sejam muitas vezes adotados como sinônimos, entendemos que têm definições distintas, conforme assumem Comte-Sponville (1995/2009), La Taille (2006), Ricoeur (1990) e Tugendhat (1996), em cuja perspectiva a moral é compreendida como um conjunto de deveres, princípios e regras que definem o que é bom ou mau, certo ou errado numa cultura e devem ser obrigatoriamente observados. Por sua vez, a ética refere-se a ideais e projetos que dão sentido à vida.

Assim, os conteúdos do plano moral estão vinculados às possibilidades de resposta à indagação "Como devo agir?" (La Taille, 2006, p. 29), enquanto à reflexão ética cabe responder à pergunta "Que vida eu quero viver?" (p. 29). Os planos moral e ético são complementares, e o sentimento que os une é o autorrespeito, isto é, qualquer estado subjetivo de valorização de si próprio, quando incide sobre valores morais (La Taille, 2006).

La Taille (2006) afirma que tudo pode tornar-se valor, uma vez que tudo é passível de investimento afetivo. Para La Taille (2001), três são os tipos de valores que podem compor as representações de si, a saber: o dos que têm relação com a moral, o dos que não têm essa relação e o dos que são contraditórios a ela. As virtudes são os nossos valores morais (Comte-Sponville, 1995/2009; La Taille, 2001). Segundo La Taille (2002), a personalidade humana corresponde a um conjunto de representações de si, que são os conceitos que cada um tem sobre si próprio e que remetem a valores.

Ainda no que tange aos valores morais, La Taille e Menin (2009) questionam se a sociedade estaria vivendo um momento de crise de valores ou um momento de valores em crise. No primeiro, os valores morais estariam "doentes", ocorrendo assim sua desvalorização; no segundo, ao contrário, os valores morais estariam sendo reinterpretados, ocorrendo um rearranjo das considerações morais. Diante disso, entende-se que o estudo dos valores morais é relevante e atual.

Retomando a discussão a respeito dos planos moral e ético, destacamos que o invariante psicológico do primeiro é o sentimento de obrigatoriedade ou dever, equivalente a

\footnotetext{
1 Adotamos o termo educação em valores morais (EVM) como sinônimo de educação moral. Tal escolha justifica-se pelo fato de muitas vezes o segundo termo ser associado à antiga disciplina Educação Moral e Cívica, que se diferencia da proposta aqui discutida; no entanto, quando fazemos menção a algum autor, citamos a nomenclatura por ele utilizada na obra referenciada.
}

uma exigência que impele o indivíduo a agir de determinada maneira. No que diz respeito ao plano ético, o invariante é a procura de sentido para a vida, ou seja, o sentimento de expansão de si próprio, a busca e manutenção de representações de si como valor positivo (La Taille, 2006).

Dessa maneira, temos que diferentes conteúdos podem estar vinculados aos planos moral e ético. Neste sentido, La Taille (2006) ressalta que devemos "[...] definir conteúdos para a moral, pois é ela que confere às 'opções de vida boa' a sua legitimidade, isto é, concede-lhes as condições necessárias para que mereçam o nome de ética" ( $p$. 60). O autor considera três virtudes: justiça, generosidade e honra, mas não descarta a importância de outras.

Com relação à justiça, Comte-Sponville (1995/2009), Kohlberg (1992) e Piaget (1932/1994) dão destaque a esse valor para a moralidade humana. De acordo com Piaget (1932/1994), ela é a mais racional das noções morais. A generosidade, diferentemente da justiça, corresponde a dar a outrem o que lhe falta sem que isto se lhe configure como um direito (La Taille, 2006). Se compararmos a generosidade com a solidariedade, vemos que a segunda, conforme Comte-Sponville (1995/2009), tem por característica o interesse e é muito ilusória para ser considerada uma virtude, pois tem por princípio agir com a intenção de receber algo em troca; no entanto, a solidariedade pode suscitar e reforçar a generosidade (Vale \& Alencar, 2009). Por fim, no que diz respeito à honra, La Taille (2006, p. 62) a define como "o valor moral que a pessoa tem aos seus próprios olhos e a exigência que faz a outrem para que esse valor seja reconhecido e respeitado". Segundo este autor, o autorrespeito corresponde ao sentimento que opera a junção entre moral e ética, enquanto a honra é o valor responsável por tal.

Exposto o que compreendemos por moral e ética e por valores morais, passamos a discutir como estes podem ser desenvolvidos.

Piaget (1932/1994) considera que os seres humanos se tornam morais por um processo de construção, isto é, não nascem sabendo avaliar o que é certo ou errado, o que é o bem ou o mal: a capacidade de avaliar se desenvolve ao longo do processo de socialização. Nesse processo, os indivíduos passam da anomia para a heteronomia, podendo alcançar a autonomia. Na anomia, a criança ainda não adentrou o universo moral, isto é, ela apresenta apenas hábitos de conduta. Por sua vez, na heteronomia, a moral começa a fazer parte dos valores dos sujeitos, predominando o respeito unilateral e as relações de coação. Por fim, na autonomia, a criança não mais julga o correto com base nas prescrições dos adultos, mas em acordos mútuos e princípios universais. Em outras palavras, Piaget (1932/1994) afirma a existência de duas morais - a heteronomia e a autonomia -, as quais se caracterizam como tendências pelas quais o sujeito pensa a moral.

Durante o desenvolvimento moral os dois tipos de respeito, o unilateral e o mútuo, são sentimentos importantes para a aquisição das noções morais (Piaget, 1932/1994). Assim, ambos são relevantes para esse desenvolvimento, 
isto é, para que o indivíduo chegue à prática do respeito mútuo, é importante a vivência do respeito unilateral.

Posto isso, podemos perguntar: o que é uma EVM? Conforme Piaget (1930/1996), não se pode falar em moral sem falar em educação, que significa, no sentido geral do termo, tudo aquilo "[...] que se sobrepõe à constituição inata do indivíduo" (p. 3). De acordo com Müller e Alencar (2012), a EVM é "o processo pelo qual os valores deixam de ser leis impostas por agentes externos e convertem-se em diretrizes internas, legitimadas pela própria pessoa" (p. 56). Assim, entendemos a EVM como o processo de desenvolvimento que consiste na construção da moralidade por parte dos indivíduos.

No que diz respeito aos objetivos desse tipo de formação, Piaget (1930/1996) considera que sejam os que levam a constituir personalidades autônomas. Por sua vez, Araújo (2000) aponta que devem ser os que propiciem aos sujeitos as ferramentas necessárias à construção de sua competência cognitiva, afetiva, cultural e orgânica, de forma a torná-los capazes de agir moralmente.

Ainda no que tange aos objetivos da EVM, Puig (2007) defende que a formação moral deve proporcionar aprendizagens éticas, ou seja, deve possibilitar ao sujeito aprender a viver: aprender a ser, aprender a conviver, aprender a participar e aprender a habitar o mundo. Aprender a ser (autoética) significa construir uma ética pessoal, uma ética de si mesmo, que inclui a formação de um pensamento autônomo e crítico que torne o indivíduo capaz de construir os próprios critérios de conduta. Aprender a conviver (alterética) equivale à tarefa formativa para superar a tendência à separação e contribuir para que os indivíduos estabeleçam vínculos pessoais baseados na compreensão do outro. Por sua vez, aprender a participar (socioética) é aprendizagem da vida em comum, é trabalhar por uma ética que torne os indivíduos cidadãos ativos, participativos. Finalmente, aprender a habitar o mundo (ecoética) é a proposta de um trabalho educativo reflexivo sobre a responsabilidade pelo planeta, pela humanidade.

Vistos os objetivos da EVM, passemos agora aos ambientes onde ela pode ocorrer. Diversos espaços sociais são apontados, como a escola, a família e outros. No tocante à escola, alguns autores (Araújo, 2000, 2001, 2007; Delors, 1996; Dias, 2005; Goergen, 2007; Kohlberg, 1992; La Taille, 2009; Menin, 1996; Piaget, 1930/1996; Puig, 2007) ressaltam a importância desse contexto para a formação em EVM. Por outro lado, a família também é um importante espaço. Dessen e Polonia (2007) destacam a relevância da família e da escola como contextos de desenvolvimento humano em que todos trabalham em conjunto para facilitar a aprendizagem e o desenvolvimento dos indivíduos.

Além de acontecer em diferentes espaços sociais, a EVM pode abordar distintos graus de consideração: a si mesmo, ao outro e à sociedade. Tais aspectos estão diretamente relacionados aos conceitos de moral e ética discutidos anteriormente, pois, conforme ensina Ricoeur (1990), a ética pode ser concebida como vida boa para si ou vida boa com e para o outro em instituições alicerçadas na justiça. Análises das considerações sobre os referidos níveis podem ser encontradas nos trabalhos de Miranda (2007) e Andrade (2012).

Como nossa pesquisa enfocou o ambiente escolar, passemos, então, para as possibilidades de procedimentos propostas para a EVM no que tange ao contexto em questão. Piaget (1930/1996) aponta dois caminhos fundamentais para a educação que vise à autonomia moral: 1- não impor à criança aquilo que ela tem a capacidade de descobrir por si; e 2- criar situações que permitam a ela compreender a necessidade e as razões das regras. Ora, essas situações de descoberta das razões e necessidade das regras podem ser as mais variadas na escola. De acordo com Piaget (1930/1996), as atividades escolares em grupo são as mais indicadas para a construção moral, pois é nelas que a cooperação é mais provocada.

Em seu texto Procedimentos da Educação Moral, Piaget (1930/1996) destaca que os métodos podem ser classificados de diferentes formas, uma das quais é a classificação quanto à técnica. Nesse domínio, Piaget (1930/1996) ressalta que podemos considerar três aspectos: "[...] conforme sejam fundamentados sobre tal e qual tipo de respeito ou relações interindividuais, conforme se utilizem de diferentes maneiras de ensino oral e conforme eles recorram ou não à própria ação da criança" (p.10). A respeito desses dois últimos aspectos, o autor menciona os procedimentos verbais e os métodos ativos.

No que concerne ao ensino oral, temos "os procedimentos verbais de educação” (Piaget, 1930/1996, p. 15), um método utilizado pelos educadores para instruir os alunos em que se conta com o discurso para educar. Outros autores apontam procedimentos que podemos considerar como exemplos de métodos verbais, a saber: o diálogo, que é um procedimento indicado pelos Parâmetros Curriculares Nacionais - PCNs - (1997); os espaços de discussão que não sejam baseados em hierarquias (Piaget, 1930/1996, 1932/1994; Puig, 2007); as disciplinas específicas (La Taille, 2009) e as discussões de dilemas (Biaggio, 1997; Kohlberg, 1992), que são apontadas como um meio de provocar reflexões a partir de um dilema instaurado.

Já "os métodos 'ativos' de educação moral" (Piaget, 1930/1996, p. 21) recorrem à própria ação da criança. São atividades que possibilitam à criança participar de experiências morais em ambientes proporcionados pela própria escola. Como exemplo, Piaget (1930/1996) cita a escola ativa, que tem por fundamento que os conteúdos ensinados às crianças não sejam impostos de fora para dentro, e sim redescobertos por meio de investigação e atividades espontâneas. Esse método está baseado na noção de self-government, ou seja, a criança discute por si mesma as leis constitutivas em situações reais.

Existem também possibilidades de procedimentos que podem ocorrer por meio de ambos os métodos, o ativo e o verbal. São esses, por exemplo, a transversalidade (MEC, 1997; La Taille, 2009; Piaget, 1930/1996) e a contextualização dos conteúdos (Biaggio, 1997; Piaget, 1930/1996). A transversalidade caracteriza-se pela integração de temas (sociais e/ou morais) às áreas convencionais de ensino. 
Nessa perspectiva, não se adota uma disciplina específica para trabalhar os conteúdos morais, que devem ser contemplados por todos os docentes nas matérias que lecionam. Também é relevante a contextualização dos conteúdos a serem trabalhados na EVM, ou seja, que eles tenham relação com situações práticas e que levem em consideração o contexto social no qual o indivíduo esteja inserido.

Tendo em vista o que foi exposto, partimos do pressuposto de que a escola é um espaço fundamental para desenvolver experiências de EVM, mas deve também favorecer o desenvolvimento moral dos indivíduos visando à autonomia. Vejamos, então, o método utilizado nesta pesquisa, a discussão que os dados obtidos suscitaram e as considerações finais sobre o presente estudo.

\section{Método}

\section{Participantes}

Nosso estudo contou com a participação de 92 profissionais da área da Educação de escolas públicas estaduais de Ensino Fundamental, $6 .^{\circ}$ a 9..$^{\circ}$ ano, e Ensino Médio das quatro mesorregiões do Estado do Espírito Santo, dos quais 30 eram da Sul Espírito-Santense, 29 da Central, 20 da Noroeste e 13 da Litoral-Norte.

\section{Instrumento}

O instrumento utilizado para a coleta de dados foi um questionário composto de questões abertas e fechadas acerca das concepções e juízos dos profissionais sobre a EVM e das possibilidades de procedimentos para esse tipo de educação. $O$ instrumento continha ainda perguntas referentes à caracterização dos respondentes, tais como sexo, função exercida na escola e ano escolar com que trabaIhava. Em relação às questões sobre concepções, juízos e procedimentos, os participantes responderam às seguintes indagações:

1. O que você entende por educação em valores morais?

2. Na sua opinião, a escola deve dar educação em valores morais a seus alunos? Por quê?

3. Se você respondeu "sim" à questão anterior, diga, em resumo, como essa educação poderia acontecer.

\section{Procedimentos de coleta de dados}

A partir de uma lista com a relação das escolas estaduais do Espírito Santo, disponibilizada pela Secretaria de Estado da Educação (Sedu), selecionamos como alvo do estudo as de Ensino Fundamental (6..$^{\circ}$ a $9 .^{\circ}$ ano) e Ensino
Médio, o que resultou em 367 escolas. Enviamos para cada uma destas escolas, via correio, um envelope contendo uma carta de apresentação da pesquisa, duas vias do Termo de Consentimento Livre e Esclarecido e dois questionários. Além disso, os profissionais tinham a possibilidade de responder ao instrumento em forma on-line. Recebemos 47 questionários respondidos on-line e 45 impressos.

Durante a pesquisa respeitamos os procedimentos éticos estabelecidos pela Resolução n. ${ }^{\circ} 196$, de 10 de outubro de 1996, do Ministério da Saúde (1996). Dessa maneira, todos os respondentes assinaram um Termo de Consentimento Livre e Esclarecido. Nesse sentido, para preservarmos a identidade dos sujeitos, utilizamos nomes fictícios quando apresentamos exemplos citados por eles, os quais correspondem às frases em negrito e entre aspas.

\section{Tratamento dos dados}

Os dados foram analisados com base na sistematização proposta por Delval (2002). Assim, priorizamos a análise qualitativa, mediante a qual foram elaboradas categorias detalhadas e resumidas das respostas dos participantes; entretanto, realizamos também uma análise quantitativa dos dados, por meio do programa Statistical Package for Social Sciences for Windows - SPSS (2010).

\section{Resultados e discussão}

É importante salientar que, embora o número total de participantes tenha sido 92, o número de respostas variou, pois para algumas perguntas havia a possibilidade de o respondente apresentar mais de uma explanação ou justificativa. Outro esclarecimento é que, para esta análise, discutimos os dados tidos como os mais relevantes. Dessa maneira, selecionamos os resultados que apareceram com maior frequência ou que, por sua relevância teórica, mereciam ser destacados.

Inicialmente, apresentamos alguns dados de caracterização dos participantes no que diz respeito a sexo, função exercida na escola e ano escolar com que trabalhavam. No que se refere ao sexo, recebemos nove questionários respondidos por profissionais do sexo masculino. Esse resultado está em consonância com os dados do Instituto Nacional de Estudos e Pesquisas Educacionais Anísio Teixeira - Inep - (2011), os quais demonstram que, no Brasil, $81,67 \%$ dos profissionais que lecionam para o Ensino Fundamental são mulheres.

No que tange às funções exercidas, a amostra contou com o percentual de $27,4 \%(n=26)$ de diretores, $25,3 \%$ $(n=24)$ de professores, 21,1\% $(n=20)$ de coordenadores pedagógicos, $15,8 \%(n=15)$ de pedagogos, $6,3 \%(n=6)$ de coordenadores e $4,1 \%(n=4)$ de participantes que exerciam outras funções, a saber: membro da equipe pedagógica, gestor educacional, supervisor pedagógico e técnico do Ensino Médio da Superintendência Municipal. Nesse caso, o número 
total de funções foi igual a 95, uma vez que alguns respondentes ocupavam mais de um cargo simultaneamente.

Com relação aos anos escolares em que os profissionais trabalhavam, constatamos um total de 151 menções: 67 $(44,4 \%)$ ao Ensino Médio, 43 (28,5\%) para turmas do $6 .^{\circ}$ ao 9. ${ }^{\circ}$ anos do Ensino Fundamental, 12 (7,9\%) para turmas de do $1 .^{\circ}$ ao $5 .^{\circ}$ anos do Ensino fundamental, oito (5,3\%) para Educação de Jovens e Adultos (EJA) e cinco (3,3\%) para ensino profissional. Encontramos um total de quatro $(2,7 \%)$ para ausência de resposta e de 12 (7,9\%) para outros, que continham citações como Educação Infantil, Educação Especial, entre outros.

Passemos agora aos dados referentes às questões propriamente ditas do estudo. A primeira delas é: "O que você entende por educação em valores morais?" Para essa questão, verificamos 190 respostas. Os dados obtidos estão apresentados na tabela 1.

No tocante às concepções dos profissionais, o maior percentual encontrado foi que a EVM está relacionada a trabalhos com valores morais ou éticos. Os participantes

Tabela 1. Definição de EVM.

\begin{tabular}{|c|c|c|}
\hline & $n$ & Porcentagem \\
\hline Valores morais ou éticos & 27 & $14,2(\%)$ \\
\hline $\begin{array}{l}\text { Relacionamentos } \\
\text { sociais, pessoais ou } \\
\text { consigo mesmo }\end{array}$ & 27 & $14,2(\%)$ \\
\hline Respeito & 20 & $10,5(\%)$ \\
\hline Juízo correto & 15 & $7,9(\%)$ \\
\hline Cidadania & 12 & $6,3(\%)$ \\
\hline Valores sociais & 12 & $6,3(\%)$ \\
\hline Princípios e normas & 10 & $5,3(\%)$ \\
\hline $\begin{array}{l}\text { Especificidade do ser } \\
\text { humano }\end{array}$ & 9 & $4,7(\%)$ \\
\hline Agir bem & 7 & $3,7(\%)$ \\
\hline $\begin{array}{l}\text { Totalidade do ser } \\
\text { humano }\end{array}$ & 6 & $3,2(\%)$ \\
\hline Solidariedade & 6 & $3,2(\%)$ \\
\hline Religiosidade & 4 & $2,1(\%)$ \\
\hline Qualidade de vida & 4 & $2,1(\%)$ \\
\hline Justiça & 4 & $2,1(\%)$ \\
\hline Dignidade & 3 & $1,6(\%)$ \\
\hline Educação para a vida & 3 & $1,6(\%)$ \\
\hline Ausência de resposta & 1 & $0,5(\%)$ \\
\hline Outros & 20 & $10,5(\%)$ \\
\hline Total & 190 & $100,0(\%)$ \\
\hline
\end{tabular}

citaram os referidos valores mas os especificaram. Temos como exemplos o argumento de Carolina, para quem a EVM é aquela que "trabalha a ética", e o de Cláudia, para quem esse tipo de educação "resgata valores morais".

Embora tenhamos adotado os conceitos de moral e ética propostos por autores como Comte-Sponville (1995/2009), La Taille (2006), Ricoeur (1990) e Tugendhat (1996), ressaltamos que o instrumento utilizado em nosso estudo não nos possibilitou apreender as concepções assumidas pelos participantes. De qualquer, sugerimos que pesquisas que utilizem o método clínico sejam realizadas para averiguar os referidos conceitos entre os profissionais de educação. Outro aspecto importante diz respeito ao argumento circular desse tipo de resposta, pois, ao dizer que educar moralmente é trabalhar moral e ética, os respondentes se utilizaram do termo para explicar o conceito.

Constatamos também um grande número de dados para a consideração de que a EVM está associada a relacionamentos sociais, pessoais ou consigo mesmo, tendo encontrado onze respostas para relacionamentos sociais, dez para pessoais e seis para consigo mesmo, como podemos verificar, respectivamente, nas seguintes afirmações: "desenvolve atitudes nos alunos que servem para melhorar a vida da sociedade" (Stéfani), "busca formar um ser humano capaz de lidar com os outros" (Naiara) e "voltada para resgatar os valores essenciais na convivência consigo mesmo" (Samanta).

Conforme mencionado anteriormente, a EVM pode abordar três distintos graus de consideração: a si mesmo, ao outro e à sociedade, conforme propuseram em suas pesquisas Andrade (2012) e Miranda (2007). Na presente pesquisa verificamos que na menção aos relacionamentos sociais há a consideração do social, ou seja, a importância da EVM para o desenvolvimento de atitudes que visem à qualidade $\mathrm{e}$ ao bem da sociedade. Também constatamos em relacionamos pessoais a menção à relação do indivíduo com o grupo no qual está inserido, o que equivale a dizer que a EVM pode possibilitar a promoção de bons relacionamentos interpessoais. Por último, em relacionamentos consigo mesmo, os respondentes levaram em conta o individual, destacando a relevância da referida educação para o relacionamento do indivíduo consigo mesmo.

$\mathrm{Na}$ categoria respeito, agrupamos as explicações nas quais os participantes apontaram diretamente esse sentimento para conceituar EVM, seja o respeito dirigido ao outro $(n=11)$ e a si mesmo $(n=3)$, seja o voltado a outras possibilidades, como à pátria, ao meio ambiente, à vida e à escola $(n=6)$. Assim, apresentamos os seguintes exemplos: "proporciona o respeito aos semelhantes" (Cássia), "desenvolve o respeito a si" (Stéfani) e "ensina o respeito à vida" (Sofia). Conforme pudemos averiguar, também encontramos nesta última categoria os graus de consideração anteriormente citados.

O respeito constitui um sentimento importante para a aquisição das noções morais, como demonstra Piaget (1932/1994). O respeito para com o outro pode configurar-se por um caráter tanto unilateral quanto mútuo, dois tipos que 
devem ser levados em consideração na formação moral dos alunos. Além disso, os profissionais também mencionaram o respeito a si mesmo, que corresponde a outro tipo relevante na construção da personalidade moral: o autorrespeito, que, conforme nos traz La Taille (2006), é o sentimento que une os planos moral e ético. Também citaram o respeito ao meio ambiente, à escola e à pátria. Neste sentido, mencionaram conteúdos que podem ser relacionados às aprendizagens éticas descritas por Puig (2007), como aprender a ser, que pode contemplar o respeito a si próprio, aprender a conviver, que envolve o respeito ao outro, e aprender a habitar o mundo, que inclui o respeito ao meio ambiente. Diante disso, destacamos a importância de a EVM desenvolver nos alunos estes tipos de respeito: ao outro, a si próprio, ao meio ambiente.

Outro dado relevante corresponde ao juízo correto, ou seja, fazer o que é certo conforme o dever, tal como podemos constatar nos seguintes exemplos: "(...) nos permite buscar critérios para definirmos o que é ser bom/ correto/moralmente certo" (Carmelita); e "(...) forma o indivíduo para que ele saiba opinar sobre o que é certo e errado" (Socorro). As respostas aqui reunidas referem-se ao sentimento de obrigatoriedade (Piaget, 1932/1994; La Taille, 2006), isto é, os participantes afirmam que a EVM deve trabalhar o plano moral e o agir por dever.

Por sua vez, os juízos sobre solidariedade e justiça, apesar de terem ocorrido com baixa frequência, merecem ser discutidos por esses temas serem relevantes para a área da EVM. Foram agrupadas em cada uma dessas categorias concepções que versam sobre o desenvolvimento desses valores especificamente: "aquela que torna os seres humanos mais solidários" (Cristina); "faz renascer valores como justiça" (Selma). Dentre as várias virtudes, os participantes relacionaram a EVM com o desenvolvimento de duas delas: justiça e solidariedade; todavia, apesar de a justiça ser central para a moralidade (Comte-Sponville, 1995/2009; Kohlberg, 1992; Piaget 1932/1994), foram poucas as respostas em que essa virtude esteve relacionada com a EVM. Tal fato também pode ser verificado no que tange à solidariedade.

Quanto à indagação sobre se a escola deve trabaIhar a EVM, 97,8\% $(n=90)$ dos profissionais responderam afirmativamente. Foram encontrados apenas 2,2\% ( $n=2)$ em ausência de resposta. Os que responderam "sim" apresentaram um total de 288 justificativas para essa questão, as quais são apresentadas na tabela 2 .

O maior percentual dos dados está relacionado às justificativas em que os participantes apontam que ministram EVM porque é função da escola oferecer esse tipo de formação, como mostra o exemplo a seguir: "(...) resgata a verdadeira função da escola" (Sofia). A escola é citada como um dos principais responsáveis pela formação moral dos indivíduos, conforme argumentou a maioria dos profissionais - argumento que está em consonância com o que é apresentado por autores como: Araújo (2000, 2001, 2007), Delors (1996), Dias (2005), Goergen (2007), Kohlberg (1992), La Taille (2009), Menin (1996), Piaget (1930/1996), Puig (2007).
Tabela 2. Justificativas para se trabalhar EVM na escola.

\begin{tabular}{|c|c|c|}
\hline & $n$ & Porcentagem \\
\hline É função da escola & 40 & $13,9(\%)$ \\
\hline Há crise de valores & 36 & $12,5(\%)$ \\
\hline $\begin{array}{l}\text { Contribui para a vivência } \\
\text { social }\end{array}$ & 28 & $9,7(\%)$ \\
\hline $\begin{array}{l}\text { Promove valores morais } \\
\text { específicos }\end{array}$ & 26 & $9,0(\%)$ \\
\hline $\begin{array}{l}\text { A família não cumpre } \\
\text { seu papel }\end{array}$ & 18 & $6,3(\%)$ \\
\hline $\begin{array}{l}\text { Resgata valores morais } \\
\text { em geral }\end{array}$ & 18 & $6,3(\%)$ \\
\hline $\begin{array}{l}\text { Promove uma } \\
\text { sociedade mais humana } \\
\text { ou justa }\end{array}$ & 18 & $6,3(\%)$ \\
\hline Forma cidadão & 17 & $5,9(\%)$ \\
\hline $\begin{array}{l}\text { Torna os seres humanos } \\
\text { mais críticos e/ou } \\
\text { autônomos }\end{array}$ & 14 & $4,9(\%)$ \\
\hline $\begin{array}{l}\text { A escola é um lugar } \\
\text { propício }\end{array}$ & 8 & $2,8(\%)$ \\
\hline $\begin{array}{l}\text { Há aumento dos } \\
\text { problemas sociais }\end{array}$ & 8 & $2,8(\%)$ \\
\hline $\begin{array}{l}\text { Promove a autocrítica } \\
\text { ou o cuidado consigo } \\
\text { mesmo }\end{array}$ & 8 & $2,8(\%)$ \\
\hline Forma pessoas éticas & 7 & $2,4(\%)$ \\
\hline $\begin{array}{l}\text { Torna o ser humano } \\
\text { mais participativo }\end{array}$ & 6 & $2,1(\%)$ \\
\hline Possibilita ações morais & 5 & $1,7(\%)$ \\
\hline $\begin{array}{l}\text { Há crescente avanço } \\
\text { da tecnologia e/ou } \\
\text { globalização }\end{array}$ & 3 & $1,0(\%)$ \\
\hline $\begin{array}{l}\text { Busca promoção da } \\
\text { qualidade de vida }\end{array}$ & 3 & $1,0(\%)$ \\
\hline $\begin{array}{l}\text { É importante na } \\
\text { formação do indivíduo }\end{array}$ & 3 & $1,0(\%)$ \\
\hline Ausência de resposta & 6 & $2,1(\%)$ \\
\hline Outros & 16 & $5,5(\%)$ \\
\hline Total & 288 & $100,0(\%)$ \\
\hline
\end{tabular}

Por outro lado, os respondentes também citaram que a escola deve oferecer EVM porque atualmente há crises de valores: "os valores do ser humano e o respeito pelo próprio ser estão sendo abandonados" (Sandra); "a sociedade vive um período de crise moral" (Nádia); "os alunos 
estão caindo no individualismo" (Neusa). Tais concepções vão ao encontro do que La Taille e Menin (2009) definem como "crise de valores", caracterizada pela concepção dos indivíduos de que os valores morais estariam ausentes, desvalorizados. Tal justificativa leva-nos a inferir que provavelmente esses profissionais avaliam que há uma "crise de valores" na atualidade; no entanto, esse aspecto precisa ser mais bem investigado em futuras pesquisas.

Além dos argumentos anteriores, os participantes justificaram ainda que a EVM contribui para a vivência social, conforme se observa nos seguintes exemplos: "norteia a convivência social" (Cecília) e "prepara os alunos para que eles saibam seu papel moral no convívio comunitário" (Cássio). Tais justificativas podem ser relacionadas às aprendizagens éticas descritas por Puig (2007), isto é, de acordo com os profissionais, a escola deve oferecer EVM porque essa formação propicia o "aprender a conviver", que diz respeito à tarefa formativa que visa ajudar os sujeitos a estabelecer vínculos pessoais baseados na compreensão do outro, assim como favorece o "aprender a participar", que corresponde à aprendizagem da vida em comum, uma ética que torna os indivíduos cidadãos ativos.

Em promove valores morais específicos agrupamos as justificativas cujo argumento era que esse tipo de educação promove valores morais como respeito $(n=07)$, solidariedade $(n=03)$, justiça $(n=01)$, entre outros, conforme podemos observar nos relatos: "resgata o respeito" (Cecília); "para que os alunos sejam solidários" (Carina) e "ajuda a promover a paz" (Cristina). Como mencionado anteriormente, o respeito é um sentimento importante na aquisição das noções morais (Piaget, 1932/1994), e virtudes como solidariedade, justiça, generosidade e honra são os nossos valores morais (Comte-Sponville, 1995/2009; La Taille, 2001).

Nas justificativas agrupadas em a família não cumpre seu papel, os profissionais apontaram a família como a responsável por educar em valores morais, e, uma vez que esta não está cumprindo o seu papel, cabe à escola assumir essa função, conforme pode ser verificado nos seguintes exemplos: "a escola assumiu o papel da família" (Cláudia); "a família está esquecida de fazer essa parte" (Carmelita); "a família abandona a responsabilidade de educar seus fiIhos" (Cibele). A EVM pode acontecer nos diversos espaços sociais em que se pode estar inseridos, entre eles, a família e a escola. Nessas justificativas, os participantes atribuem maior importância ao papel da família no que tange a esse tipo de educação. Para eles, cabe à escola ensinar moralmente, já que a família não está cumprindo esse papel. Por outro lado, diversos autores consideram que a escola é um local privilegiado para esse tipo de formação (Araújo, 2007; Delors, 1996; Goergen, 2007; Kohlberg, 1992; Menin, 1996; Piaget, 1930/1996; Puig, 2007), o que equivale a dizer que também é papel da escola educar moralmente seus alunos. Nesse sentido, Dessen e Polonia (2007) ressaltam que a família e a escola exercem papel fundamental no desenvolvimento humano em geral, e que o sucesso desse processo depende do trabalho conjunto de ambas.
Os argumentos reunidos em resgata valores morais em geral referem-se ao fato de a EVM contribuir para o desenvolvimento desses valores, segundo o que se infere destes exemplos: "contribui para o resgate de valores" (Carla); "dá forma/lapida esses valores" (Caio). Assim como explanado anteriormente, o instrumento de pesquisa não nos possibilitou investigar o que os participantes entendem por moral e por ética. Desse modo, também no que diz respeito a esses dados, não foi possível averiguar a concepção de valores morais dos respondentes. Destacamos novamente que essas justificativas são circulares, pois dizer que a escola deve oferecer EVM porque esta resgata os valores morais não esclarece a importância de essa instituição trabalhar este tipo de educação.

Com relação a promove uma sociedade mais humana ou justa, temos os seguintes exemplos: "para construirmos uma sociedade humana" (Sheila); "cabe à escola formar cidadãos que saibam fazer uma sociedade ética/justa" (Nádia); "para buscar uma educação que prime por uma sociedade justa de respeito mútuo" (Sueli).

No que tange às possibilidades de procedimentos de EVM, os respondentes apresentaram um total de 266 respostas, que foram agrupadas em métodos verbais $(39,8 \%$; $\mathrm{n}=106)$, métodos ativos $(37,2 \% ; \mathrm{n}=99)$, métodos ativos e verbais $(20,4 \% ; n=54)$ e ausência de resposta $(2,6 \% ; n=7)$.

Em métodos verbais foram inseridas considerações em que o procedimento mencionado diz respeito a um método exclusivamente verbal, por exemplo: "vídeos ou filmes" (Cassiana); "disciplinas específicas" (Sara); "palestras" (Cristina); "diálogo" (Claudimara); "debates ou conversas" (Cátia). Quanto a métodos ativos, as explanações se referem a uma ação, como nos exemplos a seguir: "vivências ou práticas" (Carmem); "projetos" (Cláudia); "dinâmicas ou oficinas" (Cássio); e "abordagens lúdicas" (Cibele). Por sua vez, em métodos ativos e verbais estão os argumentos em que os respondentes listam instrumentos que poderiam ser utilizados na EVM, a partir dos quais não foi possível inferir o tipo de método adotado, como é o caso de "contextualização dos conteúdos" (Carmelita). Pudemos constatar que os métodos verbais foram os mais citados, porém houve pouca diferença com relação ao percentual de métodos ativos.

No que diz respeito aos métodos verbais, os profissionais citaram diferentes procedimentos que poderiam ser adotados na EVM, como disciplinas específicas, que são indicadas por La Taille (2009) como um método possível para esse tipo de formação. Outro procedimento, o diálogo, é abordado pelos PCNs (1997), e autores como Piaget (1930/1996, 1932/1994) e Puig (2007) ressaltam a importância dele para o desenvolvimento moral dos indivíduos. Além desses, os profissionais também citaram o debate e a conversa como meios para trabalhar a EVM.

Quanto aos métodos ativos, Piaget (1930/1996) ressalta a importância que têm para a educação moral. Entre esses tipos de procedimento podemos incluir as atividades nomeadas pelos participantes como vivências ou práticas, projetos, abordagens lúdicas e dinâmicas ou oficinas, as 
quais podem proporcionar uma participação ativa dos alunos no processo da EVM.

Em métodos ativos ou verbais os profissionais mencionaram a contextualização dos conteúdos na abordagem dos assuntos morais, assim como sublinhado por Piaget (1930/1996) e Biaggio (1997). Por último destacamos, entre as possibilidades citadas pelos respondentes, a transversalidade, que é proposta pelos PCNs (1997) e por autores como Piaget (1930/1996) e La Taille (2009).

Posto isso, tecemos a seguir as considerações elaboradas com base nos dados e análises aqui apresentados.

\section{Considerações finais}

Pela análise dos dados constatamos que o respeito, a solidariedade e a justiça foram mencionados pelos participantes em duas questões: na primeira, em que os respondentes apresentaram explanações sobre o conceito de EVM, 20 das 180 respostas mencionavam que a EVM trabalha o respeito, seis a solidariedade e quatro, a justiça; e na segunda, em que os profissionais apresentaram razões pelas quais a escola deve dar EVM, das 20 respostas da categoria promove valores morais específicos, sete são de respeito, três de solidariedade e uma de justiça.

Entendemos que o respeito foi mais mencionado do que a justiça e a solidariedade tanto para explicar o conceito de EVM quanto para justificar por que a escola deve dar esse tipo de educação. Tal fato pode estar relacionado a uma preocupação maior dos participantes com a falta de respeito vivenciada no contexto escolar na atualidade, porém esse aspecto precisa ser mais bem investigado.

No tocante à justiça e à solidariedade, apesar de serem temas centrais na área da moralidade, tais conteúdos apareceram pouco nas respostas e justificativas dos participantes, fato que nos permite questionar se os profissionais da Educação se embasaram ou não em autores da área da Psicologia da Moralidade no momento em que preencheram o questionário para responder às perguntas a respeito da EVM. Além desse aspecto, verificamos, por exemplo, que os profissionais, quando argumentaram que ministrar a EVM é uma função da escola, fundamentaram suas respostas e justificativas no que propõem autores da área da Psicologia da Moralidade; contudo, conforme mencionamos, não foi possível analisar se os participantes se embasaram nessas teorias.

Por sua vez, no que tange às possibilidades citadas de procedimentos para a EVM, encontramos que os participantes mencionaram meios que podem ser classificados como métodos verbais e ativos. Também constatamos que, embora os métodos verbais tenham sido encontrados em maior número, a diferença percentual entre o primeiro e o segundo foi pequena.

Assim, constatamos que os respondentes expuseram uma diversidade de concepções a respeito da EVM e também de métodos que podem ser empregados no traba-
Iho com valores morais. Constatamos, ainda, que os participantes afirmam que a EVM deve ser trabalhada pela escola.

Neste contexto perguntamos: como promover esse tipo de formação no contexto escolar? Na introdução deste texto buscamos apresentar as propostas de alguns autores e, conforme discutido, concluímos que não existe apenas um único meio de trabalhar a formação moral dos alunos, mas uma diversidade de temas e métodos; porém é necessário que os educadores sejam formados e preparados para esse tipo de proposta, uma vez que a EVM deve direcionar e propiciar o desenvolvimento de sujeitos autônomos.

Com base no que foi exposto, destacamos, ainda, a necessidade de serem realizadas novas pesquisas na área da EVM. Um ponto que deve ser mais bem investigado diz respeito à concepção dos participantes sobre moral e ética, pois estes termos foram mencionados, mas não nos foi possível averiguar o significado que atribuíam a eles. Além disso, é importante verificar se esses conceitos têm ou não influência sobre a compreensão dos profissionais a respeito das concepções e possibilidades de procedimentos para a EVM.

Os dados que acabamos de apresentar podem servir de subsídios para que políticas públicas sejam implementadas visando à capacitação e ao aperfeiçoamento dos educadores no que diz respeito à EVM. Como a escola é um importante espaço social para esse tipo de educação, é necessário que os profissionais envolvidos nesse ambiente sejam capazes de orientar a formação dos alunos para o desenvolvimento da autonomia. Diante disso, construir conhecimentos a respeito da finalidade e dos procedimentos possíveis para a EVM é fundamental para que ela ocorra efetivamente.

\section{Referências}

Andrade, A. N. (2012). Ecos do Silêncio: juízos de surdos no âmbito da formação superior sobre projetos de vida e humilhação nas perspectivas moral e ética. Tese de Doutorado, Universidade Federal do Espírito Santo, Vitória, ES.

Araújo, U. F. (2000). Escola, democracia e a construção de personalidades morais. Educação e Pesquisa, 26(2), 91-107.

Araújo, U. F. (2001). O ambiente escolar cooperativo e a construção do juízo moral infantil: sete anos de estudo longitudinal. Revista on-line da biblioteca prof. Joel Martins, 2(2), 1-12.

Araújo, U. F. (2007). A construção social e psicológica dos valores. Em V. A. Arantes (Org.), Educação e valores: pontos e contrapontos (pp.17-64). São Paulo: Summus.

Biaggio, A. M. B. (1997). Kohlberg e a "Comunidade Justa": promovendo o senso ético e a cidadania na escola. Psicologia: Reflexão e Crítica, 10(1), 47-69. 
Comte-Sponville, A. (2009). Pequeno tratado das grandes virtudes (E. Brandão, Trad., 2a ed.). São Paulo: Martins Fontes. (Trabalho original publicado em 1995)

Delors, J. (1996). Educação: um tesouro a descobrir. Relatório para a UNESCO da Comissão Internacional sobre Educação para o século XXI. (J. C. Eufrázio, Trad.). Rio de Janeiro: Cortez editora.

Delval, J. (2002). Introdução à prática do método clínico: descobrindo o pensamento das crianças. (F. Murad, Trad.). Porto Alegre: Artmed.

Dessen, M. A., \& Polonia, A. C. (2007). A família e a escola como contextos de desenvolvimento humano. Paidéia, 17(36), 21-32.

Dias, A. A. (2005). Educação moral e autonomia na educação infantil: o que pensam os professores. Psicologia: Reflexão e Crítica, 18(3), $370-380$.

Goergen, P. L. (2007). Educação moral hoje: cenários, perspectivas e perplexidades. Educação e Sociedade, 28(100 - especial), 737762.

Instituto Nacional de Estudos e Pesquisas Educacionais Anísio Teixeira. (2011). Sinopses Estatísticas da Educação Básica. Brasília. Recuperado: 4 abr 2012. Disponível: http://portal.inep. gov.br/basica-censo-escolar-sinopse-sinopse

Kohlberg, L. (1992). Psicologia del desarollo moral. Spain: Desclée de Brouwer.

La Taiile, Y. (2009) Formação ética: do tédio ao respeito de si. Porto Alegre: Artmed.

La Taille, Y. (2001). A questão da indisciplina: ética, virtudes e educação. Em P. Demo, Y. La Taille \& J. Hoffmann (Orgs.), Grandes pensadores em educação: o desafio da aprendizagem, da formação moral e da avaliação (pp. 67-98). Porto Alegre: Mediação.

La Taille, Y. (2002). Vergonha, a ferida moral. Petrópolis, RJ: Vozes.

La Taille, Y. (2006). Moral e Ética: dimensões intelectuais e afetivas. Porto Alegre: Artmed.

La Taille, Y., \& Menin, M. S. S. (2009). Prefácio do livro Crise de valores ou valores em crise. Em Y. La Taille \& M. S. S. Menin (Org.), Crise de valores ou valores em crise. Porto Alegre: Artmed.
Menin, M. S. S. (1996). Desenvolvimento moral. Em L. Macedo (Org.), Cinco estudos de educação moral (pp. 37-104). São Paulo: Casa do Psicólogo.

Ministério da Educação e Cultura. (1997). Parâmetros Curriculares Nacionais. Brasília: Secretaria de Educação Fundamental.

Ministério da Saúde. (1996). Resolução 196/96: Diretrizes e normas regulamentadoras de pesquisas envolvendo seres humanos. Brasília.

Miranda, F. H. F. (2007). Projetos de vida na adolescência: um estudo no campo da ética e da moralidade. Dissertação de Mestrado, Universidade Federal do Espírito Santo, Vitória,ES.

Müller, A., \& Alencar H. M. (2012). Educação moral: o aprender e o ensinar sobre justiça na escola. Educação e Pesquisa, 38(2), 453468.

Piaget, J. (1994). O Juízo moral na criança. São Paulo: Summus. (Trabalho original publicado em 1932)

Piaget, J. (1996). Os procedimentos de Educação Moral. Em L. Macedo (Org.), Cinco estudos de educação moral (pp. 1-36). São Paulo: Casa do Psicólogo. (Trabalho original publicado em 1930)

Puig, J. M. (2007). Aprender a viver. Em V. A. Arantes (Org.) Educação e valores: pontos e contrapontos (pp. 65-106). São Paulo: Summus.

Ricoeur, P. (1990). Soi-même comme un autre. Paris: Seuil.

SPSS for Windows (2010). Statistical Package for Social Sciences. Base 18.0. Application Guide. Chicago, IL.

Tugendhat, E. (1996). Lições sobre ética (Grupo de doutorandos do curso de pós-graduação em Filosofia da Universidade Federal do Rio Grande do Sul, Trad.). Petrópolis, RJ: Vozes.

Vale, L. G., \& Alencar, H. M. (2009). Generosidade para com Amigo, Desconhecido e Inimigo: Juízos Morais de Crianças e Adolescentes. Interação em Psicologia, 13(2), 299-310. 


\section{Sobre as autoras}

Heloisa Moulin de Alencar (heloisamoulin@gmail.com)

Psicóloga. Doutora em Psicologia. Professora do Departamento de Psicologia Social e do Desenvolvimento, e do Programa de Pós-Graduação em Psicologia da Universidade Federal do Espírito Santo (PPGP/Ufes).

Barbara Frigini De Marchi (barbara.fdm@hotmail.com)

Graduanda em Psicologia pela Ufes.

Leandra Lúcia Moraes Couto (leandrabj@hotmail.com)

Psicóloga. Mestranda em Psicologia pelo PPGP da Ufes.

Mariana Santolin Romaneli (marianaufes@yahoo.com.br)

Psicóloga. Mestranda pelo PPGP da Ufes.

Mayara Gama de Lima (mayaragl@gmail.com)

Graduanda em Psicologia pela Ufes.

Este estudo faz parte de uma pesquisa realizada em nível nacional, por um grupo de pesquisadores participantes da Associação Nacional de Pós-Graduação em Psicologia (Anpepp), especificamente o Grupo de Trabalho Psicologia e Moralidade, cujos membros pertencem a diferentes Universidades brasileiras. Tal trabalho contou com o apoio do Conselho Nacional de Desenvolvimento Científico e Tecnológico (CNPq), sob o número 470607/2008-4.

As autoras agradecem tanto à Prof ${ }^{\mathrm{a}} \mathrm{Dr}^{\mathrm{a}}$ Maria Suzana de Stefano Menin, que coordenou o referido estudo em nível nacional, como à Prof ${ }^{\mathrm{a}} \mathrm{Dr}^{\mathrm{a}}$ Luciana Souza Borges por sua participação até o momento da coleta de dados, no que se refere à pesquisa no Espírito Santo.

As autoras são gratas, ainda, ao Programa Institucional de Iniciação Científica (Piic) da Ufes, pelas bolsas concedidas para a realização da pesquisa mediante as seguintes agências de fomento: Fundação de Amparo à Pesquisa do Espírito Santo (Fapes), Universidade Federal do Espírito Santo (Ufes), Fundo de Apoio à Ciência e Tecnologia de Vitória (Facitec). 